\title{
An epidemiological study after a water contamination incident near Worcester, England in April 1994
}

\author{
Sarah E Fowle, Claire E Constantine, David Fone, Brian McCloskey
}

\begin{abstract}
Study objectives - To investigate whether exposure to tap water contaminated in a major river pollution incident with 2 ethyl 5,5 dimethyl 1,3 dioxane (EDD) and 2 ethyl 4 methyl 1,3 dioxolane (EMD) was associated with an increase of self reported symptoms. To assess the extent of association between noticing the water had an unusual taste or odour and self reported symptoms.
\end{abstract}

Design - Retrospective cohort study.

Setting - A city and two nearby towns in a semi-rural area of England, UK.

Participants - A total of 3861 people who replied to a postal questionnaire asking about symptoms and water consumption sent to a sample of 1000 households in each of three areas - one area supplied with contaminated water (study group) and two control areas that were unaffected (control groups).

Main results - The household response rates were $65 \%$ for the study group and $56 \%$ and $57 \%$ for the two control groups. Self reporting of 10 individual symptoms was significantly increased in the study group compared with controls. Within the study group, reporting of one or more symptoms was significantly higher in subjects who consumed contaminated water but not among subjects who used it to wash or cook. Subjects who drank contaminated water showed a dose-response relationship for self reporting of one or more symptoms and for seven individual symptoms. Within the study group, however, only $62 \%$ (867 of 1398 subjects) noticed that the water had an unusual taste or odour. Among subjects who did not notice that the water had an unusual taste or odour, no association was found between drinking contaminated water and reporting one or more symptoms, or between drinking contaminated water and reporting of individual symptoms, although a doseresponse relationship was shown between the amount of water consumed and self reporting of nausea. Among subjects who noticed the water had an unusual taste or odour, both an association and a doseresponse relationship were found between consumption of contaminated water and the self reporting of six symptoms - diarrhoea, nausea, headache, stomach pains, skin irritation, and itchy eyes.
Conclusions - Higher rates of symptom reporting were associated with the water contamination incident. Reported symptoms seemed, however, to be associated with the ability to detect an unusual taste or odour in the water. Because concentrations of the contaminants would be expected to be evenly distributed in the tap water in the affected area, irrespective of taste or odour, and because of the known toxicity of the parent compounds of EMD and EDD, it is concluded that the increase in self reported symptoms in the study group respondents was associated with noticing the unpleasant taste or odour of the tap water and not with the chemical contamination. It is concluded that the observed increase in reporting of nausea with increasing water consumption was due to public anxiety caused by the incident but did not pose a serious risk to the public's health. The increase in self reported symptoms in the area affected by the contamination was an important reminder of the wider health implications of "health scares".

(f Epidemiol Community Health 1996;50:18-23)

During the morning of Friday 15 April 1994 the local water company received a considerable increase in the number of complaints from the public concerning an unusual taste and odour in the drinking water in Worcester city. Initially unidentified organic chemical contaminants were detected in very low concentrations in the consumer drinking water leaving the water treatment works at Barbourne in Worcester where water is abstracted from the River Severn. People in Worcester were advised through local media releases from $12.25 \mathrm{pm}$ on Friday not to drink the water and this advice was extended to include affected areas south of Worcester in the afternoon and evening. The population of Evesham was initially advised not to use the water, but once the area of contamination had been confirmed, this advice was withdrawn. An estimated 160000 people were living in the affected area and bowsers were deployed to provide an emergency water supply throughout Worcester city and affected towns and villages. The public were advised they could drink the water again at $5.15 \mathrm{pm}$. on Saturday 16 April after toxicology advice which confirmed that chemicals in this class were not expected to be harmful to health 
Table 1 Questionnaire returns by area

\begin{tabular}{lclll}
\hline Area & $\begin{array}{l}\text { Households } \\
\text { responding }\end{array}$ & $\begin{array}{l}\text { Response } \\
\text { rate (\%) }\end{array}$ & $\begin{array}{l}\text { Questionnaires } \\
\text { returned }\end{array}$ & $\begin{array}{l}\text { Persons at home } \\
\text { during study period }\end{array}$ \\
\hline Study & 651 & 65 & 1416 & 1398 \\
Control 1 & 557 & 56 & 1132 & 1099 \\
Control 2 & 566 & 57 & 1313 & 1262 \\
Total & 1774 & 59 & 3861 & 3759 \\
\hline
\end{tabular}

at the levels at which they had been detected. The exact configurations of the chemicals were confirmed later as two little known solvents, 2 ethyl 4 methyl 1,3 dioxolane (EMD) and 2 ethyl 5,5 dimethyl 1,3 dioxane (EDD). The water continued to smell at various points in the distribution system throughout the following week despite the fact that concentrations of the chemicals had been reduced approximately 10 fold by the addition of powdered active charcoal to the water treatment process at Barbourne works.

A total of 111 people reported either to the help line set up by the health authority, their GP, or the accident and emergency department that they had symptoms over the weekend attributed to use of tap water. Reported symptoms were mainly nausea and headache. No previous epidemiological study has been published on contamination of drinking water by these two solvents. Therefore an epidemiological study was initiated with the objectives:

- To establish whether an increase in self reported symptoms had occurred and if so, whether it was associated with use of contaminated water.

- To assess the extent of association between noticing the water had an unusual taste or odour and reporting of symptoms.

\section{Methods}

One study group and two control groups were created: a sample of private households in Worcester (study area) who received their water direct from Barbourne water treatment works, (this group would have had the highest level of contamination in the affected area); a sample of households in Evesham (control area 1), where the population was initially advised they were affected; and a sample of households in Droitwich (control area 2), selected for its geographical proximity to the study area and as it was known to be unaffected because of its borehole water supply. The three areas were known to have different population structures from one another and therefore analysis includes standardisation by age and sex.

Assuming a background symptom reporting rate of $10 \%$ and on the basis that a $5 \%$ increase in symptom reporting in the study population is an important difference, detection with $90 \%$ power and $95 \%$ confidence required approximately 1000 individuals from each area. Assuming a $50 \%$ response rate and that there were on average two persons per household, a sample of 1000 households was needed. Therefore 1000 private households in each of these three areas were selected from the water com- pany's customer database in two stages; 988 systematically sampled from non-metered account holders and 12 randomly sampled from a separate list of metered account holders.

Four detailed questionnaires were sent to each household on 22 April, one week after the onset of the incident. A telephone number was supplied so that more copies could be requested if necessary. A reminder letter was sent out after $2 \frac{1}{2}$ weeks to the 1861 households that had not replied by 9 May. Questionnaires returned up to the 10 June ( 8 weeks after the incident) were included in the analysis.

Information was requested for each member of the household. This included age, sex, normal water consumption, whether the individual had been at home at any time during the three days Friday 15 to Sunday 17th inclusive, whether tap water was consumed during the three days, and whether water was used for washing, cooking, or cleaning teeth. In addition, there were questions on other sources of water consumed, any symptoms experienced during the incident, and whether medical advice had been sought.

When it was stated that water had been consumed at "work", place of work was assumed not to be in the affected area unless stated. Where "school" was stated, however, it was assumed to be in the area of residence.

Exposure was defined as contact with or drinking of contaminated water whether or not it was noticed to be unusual in taste or odour.

Returns from households that were not on the original mailing list were excluded. Double data entry was performed and $100 \%$ validation and data analysis were carried out using Epi Info v5.

The possibility of bias due to intrahousehold correlation of responses was investigated in respect of symptom reporting. The first registered member of each household was sampled from each of the study and control groups and the level of symptom reporting was compared for each group with that where all household members are included.

Where rates were standardised by age and sex, four age groups were used - 0-24 years, 25-44 years, 45-64 years, and 65 years and over. Symptom reporting in the study group was compared for increasing levels of water consumption using $\chi^{2}$ for trend and stratification was performed using the MantelHaenszel method as calculated by Epi Info.

\section{Results}

Questionnaires were returned from a total of 3861 individuals of whom 3759 were at home at sometime during the three days under investigation. The response rates of households

Table 2 Self reported illness by area

\begin{tabular}{|c|c|c|}
\hline Group & $\begin{array}{l}\% \text { of each group } \\
\text { reporting } \geq 1 \\
\text { symptoms }\end{array}$ & $\begin{array}{l}\text { Average number of symptoms } \\
\text { reported among those reporting } \\
\geq 1 \text { symptoms }\end{array}$ \\
\hline $\begin{array}{l}\text { Study } \\
\text { Control } 1 \\
\text { Control } 2\end{array}$ & $\begin{array}{r}17 \\
7 \\
7\end{array}$ & $\begin{array}{l}2 \cdot 4 \\
3 \cdot 1 \\
3 \cdot 0\end{array}$ \\
\hline
\end{tabular}


Table 3 Self reporting of symptoms by area

\begin{tabular}{|c|c|c|c|c|}
\hline \multirow[b]{2}{*}{ Symptom } & \multicolumn{3}{|c|}{$\%$ reporting individual symptoms* } & \multirow{2}{*}{$\begin{array}{l}\chi^{2} p \text { value for comparison between } \\
\text { study } \mathcal{E} \text { combined control groups }\end{array}$} \\
\hline & Study & Control 1 & Control 2 & \\
\hline Diarrhoea & $5 \cdot 8$ & $2 \cdot 7$ & $2 \cdot 7$ & $3.2 \times 10^{-6} \mathrm{~g}$ \\
\hline Nausea & $6 \cdot 3$ & $2 \cdot 4$ & $1 \cdot 8$ & $<1 \times 10^{-7} 8$ \\
\hline Vomiting & 0.9 & $1 \cdot 1$ & 1.8 & 0.191 \\
\hline Headache & $5 \cdot 7$ & $3 \cdot 5$ & $3 \cdot 1$ & $4.9 \times 10^{-4} \mathrm{~S}$ \\
\hline Stomach pains & $6 \cdot 0$ & $3 \cdot 3$ & $2 \cdot 8$ & $1.6 \times 10^{-5}$ \\
\hline Skin irritation & $1 \cdot 7$ & 0.5 & $0 \cdot 3$ & $4.9 \times 10^{-5} \widehat{y}$ \\
\hline Tiredness & $4 \cdot 0$ & $2 \cdot 8$ & $2 \cdot 4$ & $0.020 t$ \\
\hline Itchy eyes & $1 \cdot 4$ & 0.7 & $0 \cdot 2$ & $0.002 \ddagger$ \\
\hline Sore throat & 3.5 & $1 \cdot 4$ & 1.5 & $5.1 \times 10^{-5} \mathrm{~g}$ \\
\hline Sore mouth & 1.4 & 0.8 & $0 \cdot 2$ & $0.003 \ddagger$ \\
\hline Dizziness & 1.9 & 1.4 & $0 \cdot 7$ & $0.028 \dagger$ \\
\hline Shivers & 0.9 & $1 \cdot 2$ & 0.8 & 0.969 \\
\hline Joint pains & $1 \cdot 1$ & $1 \cdot 3$ & $0 \cdot 8$ & 0.999 \\
\hline
\end{tabular}

* Directly standardised by age and sex.

+ Significant at the $5 \%$ level.

¥ Significant at the $1 \%$ level.

₹ Significant at the $1 \%$ level.
S Significant at the $0 \cdot 1 \%$ level.

Table 4 Reporting of any other illness by area

\begin{tabular}{lllll}
\hline & $\begin{array}{l}\text { \% reporting any other } \\
\text { illness in the past 2 } \\
\text { weeks }\end{array}$ & $\begin{array}{l}\text { \% taking prescribed } \\
\text { treatment for recent } \\
\text { illness }\end{array}$ & $\begin{array}{l}\text { \% reporting a } \\
\text { long term } \\
\text { illness }\end{array}$ & $\begin{array}{l}\text { \% taking } \\
\text { regular } \\
\text { medication }\end{array}$ \\
\hline Study & 10 & $4 \cdot 2$ & 20 & 26 \\
Control 1 & 14 & $5 \cdot 1$ & 17 & 33 \\
Control 2 & 13 & $7 \cdot 3$ & 20 & 26 \\
$\chi^{2}$ p value & $0 \cdot 344$ & 0.501 & 0.692 & 0.556 \\
\hline
\end{tabular}

were $56 \%$ and $57 \%$ for the control areas and $65 \%$ for the study area (table 1 ).

The study group and control group 1 had age and sex distributions that differed significantly from the 1991 census estimates for their populations in that there were proportionally more women and older people among responders.

A higher proportion of subjects in the study group reported symptoms compared with either of the two control groups (table 2), although the average number of symptoms they reported was lower.

Of those who were ill, a day of onset was not provided for $7 \%$ of the study group, $17 \%$ of control group 1, and $11 \%$ of control group 2. Some of those who reported illness therefore may have had dates of onset before the investigation period.

The duration of symptoms ranged from one hour to 10 days with an average of two days among those reporting any symptoms. Only six people felt so unwell that they visited their GP, and 11 stayed away from work or school for a day or two.

Since the same rate of illness is reported in both control groups they are combined in statistical comparisons in the remainder of the analysis.

Analysis of the effect of intrahousehold similarities in response found that selecting only one representative from each household gave
Table 6 Symptom reporting in the study group by amount of water consumed

\begin{tabular}{llll}
\hline $\begin{array}{l}\text { Amounts of } \\
\text { contaminated } \\
\text { water consumed }\end{array}$ & $\begin{array}{l}\text { No of people } \\
\text { reporting } \\
\geq 1 \text { symptoms }\end{array}$ & $\begin{array}{l}\text { No of people } \\
\text { reporting } \\
\text { no symptoms }\end{array}$ & $\begin{array}{l}\text { \% of people } \\
\text { reporting } \\
\geq 1 \text { symptoms }\end{array}$ \\
\hline None & 32 & 275 & $10 \cdot 4$ \\
$1-2$ cups & 28 & 219 & $11 \cdot 3$ \\
$3-4$ cups & 50 & 224 & $18 \cdot 2$ \\
$5-9$ cups & 66 & 205 & $24 \cdot 3$ \\
$10+$ cups* & 40 & 160 & $20 \cdot 0$ \\
Not stated $\dagger$ & 21 & 78 & $21 \cdot 2$ \\
$\chi^{2}$ for trend, p value $=0.001 \ddagger$ &
\end{tabular}

* Average $=17$ cups.

† Not included in calculation of $\chi^{2}$ for trend.

¥This illustration dose response relationship between drinking the contaminated water and reporting symptoms also held true when adjusted for age and sex. The $\chi^{2}$ trend $p$ value adjusted for age and sex is $6.5 \times 10^{-4}$ and is therefore also significant at for age and sex
the $0 \cdot 1 \%$ level.

no difference in the proportion of subjects who reported one or more symptoms. There was also no difference in the proportion reporting any specific symptom. Both findings held true for all three groups.

Ten of the 13 suggested symptoms were reported by a significantly higher proportion of study group subjects compared to subjects in the control groups (table 3). Symptoms mentioned under the category of "other" were general symptoms such as gastrointestinal upsets, peculiar sensations in the mouth, and swollen glands.

There was no significant difference between the study and control groups in reported rates of recent illness, recently prescribed treatment long term illness or regular medication (table 4).

Subjects in the study group were significantly more likely to report symptoms if they consumed contaminated water but not if they were only in contact with it (table 5). Two specific symptoms, nausea and headache, were examined to see if they were individually associated with using the water for washing, cooking, and cleaning teeth as opposed to not using it at all, and no association was found.

Subjects in the study group were also significantly more likely to report symptoms with increasing consumption of contaminated water (table 6). A significant dose-response relationship was found for seven individual symptoms: diarrhoea, nausea, headache, stomach pains, skin irritation, tiredness, and itchy eyes.

In the study group, $62 \%$ of subjects noticed the water had an unusual taste or odour at some time during the three days, although all were supplied with contaminated water. A comparison is made below between those who noticed the water had an unusual taste or odour and those who did not.

Table 5 Symptom reporting in the study group by category of exposure

\begin{tabular}{|c|c|c|c|c|}
\hline Study group & $\begin{array}{l}\text { No of people } \\
\text { reporting } 1 \text { or } \\
\text { more symptoms }\end{array}$ & $\begin{array}{l}\text { No of people } \\
\text { reporting } \\
\text { no symptoms }\end{array}$ & $\begin{array}{l}\% \text { of people } \\
\text { reporting } \geq 1 \\
\text { symptoms }\end{array}$ & $\chi^{2} p$ value \\
\hline \multirow{3}{*}{$\begin{array}{l}\text { Drank mains water }+/- \text { washed, } \\
\text { cooked, or cleaned teeth } \\
\text { Did not drink mains water but } \\
\text { washed, cooked, or cleaned teeth } \\
\text { Did not } \text { use mains water only }\end{array}$} & 202 & 857 & $19 \cdot 1$ & \multirow{5}{*}{$\begin{array}{l}\text { Drank } v \text { did not drink \& did } \\
\text { not use, } \mathrm{p} \text { value }=5.5 \times 10^{-4 *} \\
\text { Did not drink } v \text { did not use, } \\
\mathrm{p} \text { value }=0.302\end{array}$} \\
\hline & 19 & 132 & $12 \cdot 6$ & \\
\hline & & & & \\
\hline bottled or tanker water & 13 & 143 & $8 \cdot 3$ & \\
\hline Not stated & 3 & 29 & $9 \cdot 4$ & \\
\hline
\end{tabular}

* Significant at the $0 \cdot 1 \%$ level. 
Table 7 Symptom reporting in the study group by noticing of unusual water

\begin{tabular}{|c|c|c|c|c|}
\hline Group & $\begin{array}{l}\text { No of people } \\
\text { reporting } \geq 1 \\
\text { symptoms }\end{array}$ & $\begin{array}{l}\text { No of people } \\
\text { reporting no } \\
\text { symptoms }\end{array}$ & $\begin{array}{l}\% \text { of people } \\
\text { reporting } \geq 1 \\
\text { symptoms }\end{array}$ & $\chi^{2}$ \\
\hline $\begin{array}{l}\text { Study: } \\
\text { Those noticing the water smelt or } \\
\text { tasted unusual }\end{array}$ & 191 & 675 & $22 \cdot 1$ & $\begin{array}{l}\text { Between two study } \\
\text { groups } p<1 \times 10^{-1 *}\end{array}$ \\
\hline $\begin{array}{l}\text { Study: } \\
\text { Those not noticing the water smelt or } \\
\text { tasted unusual }\end{array}$ & 46 & 486 & $8 \cdot 6$ & \multirow[t]{2}{*}{$\begin{array}{l}\text { Between study group not } \\
\text { noticing odour and } \\
\text { controls, } p=0.155\end{array}$} \\
\hline Controls: all & 160 & 2201 & $6 \cdot 8$ & \\
\hline
\end{tabular}

${ }^{*}$ Significant at the $0 \cdot 1 \%$ level

The rate of reporting one or more symptoms in the study group was significantly higher for those who noticed the water had an unusual taste or odour. The rate among those who did not notice an unusual taste or odour was not significantly different from the rate in the control groups (table 7). Individual symptom reporting rates among those who did not notice an unusual taste or odour were also not significantly different from the rate in the combined controls.

After adjustment for noticing an unusual taste or odour, as well as age and sex, a doseresponse relationship was still exhibited between amount of water consumed and reporting 1 or more symptoms (table 8 ). However, no significant relationship was found for those not noticing the water had an unusual taste or odour.

Of the seven symptoms shown to be associated with drinking contaminated water in a dose-response relationship, only nausea is associated for subjects who drank contaminated water which they did not notice as

Table 8 Symptom reporting in the study group by amount of water consumed and noticing the water was unusual

\begin{tabular}{|c|c|c|c|c|}
\hline \multirow{2}{*}{ Exposure level } & \multicolumn{2}{|c|}{$\begin{array}{l}\text { Drank contaminated water that was } \\
\text { noticed to smell or taste unusual }\end{array}$} & \multicolumn{2}{|c|}{$\begin{array}{l}\text { Drank contaminated water that was } \\
\text { not noticed to smell or taste unusual }\end{array}$} \\
\hline & $\begin{array}{l}\% \text { reporting } \\
\text { symptoms }\end{array}$ & $O R_{(M-H)}$ & $\begin{array}{l}\text { \% reporting } \\
\text { symptoms }\end{array}$ & $O R_{(M-H)}$ \\
\hline $\begin{array}{l}\text { None } \\
1-2 \text { cups } \\
3-4 \text { cups } \\
5-9 \text { cups } \\
10+\text { cups } \\
\text { Not stated* } \\
\chi^{2} \text { for trend } \dagger \\
\chi^{2} \text { for trend } \neq\end{array}$ & $\begin{array}{l}12 \cdot 3 \\
23 \cdot 0 \\
30 \cdot 5 \\
40 \cdot 0 \\
24 \cdot 4 \\
36 \cdot 6 \\
\text { p value }=4\end{array}$ & $\begin{array}{l}1 \cdot 00 \\
2 \cdot 22 \\
3 \cdot 09 \\
4.94 \\
2 \cdot 29 \\
5 \\
\text { p value }=3 \times 10^{-5}\end{array}$ & $\begin{array}{c}6 \cdot 4 \\
5 \cdot 2 \\
10 \cdot 5 \\
13 \cdot 9 \\
10 \cdot 3 \\
8 \cdot 6 \\
\text { p value }=0\end{array}$ & $\begin{array}{l}1.00 \\
0.83 \\
1.69 \\
2 \cdot 15 \\
1.69\end{array}$ \\
\hline
\end{tabular}

* Not included in $\chi^{2}$ for trend.

+ Stratified for by age and sex.

¥ Stratified for by age, sex, and noticing the water smelt or tasted unusual.

Table 9 Symptom reporting in the study showing a dose response relationship to amount of water consumed among those who did and did not notice the water was unusual.

\begin{tabular}{|c|c|c|}
\hline \multirow[b]{2}{*}{ Symptom } & \multicolumn{2}{|l|}{$\chi^{2}$ for trend $d^{*}, p$ value } \\
\hline & $\begin{array}{l}\text { Contaminated water that was } \\
\text { noticed to smell or taste unusual } \dagger\end{array}$ & $\begin{array}{l}\text { Contaminated water that was not } \\
\text { noticed to smell or taste unusual }\end{array}$ \\
\hline $\begin{array}{l}\text { Diarrhoea } \\
\text { Nausea } \\
\text { Headache } \\
\text { Stomach pains } \\
\text { Skin irritation } \\
\text { Tiredness } \\
\text { Itchy eyes }\end{array}$ & $\begin{array}{l}4 \cdot 1 \times 10^{-4} \S \\
0.003^{* *} \\
4 \cdot 1 \times 10^{-4} \S \\
<1 \times 10^{-6} \$ \\
8 \cdot 6 \times 10^{-4} \\
0 \cdot 304 \\
0 \cdot 009^{* *}\end{array}$ & $\begin{array}{l}0.751 \\
0.02+t \\
0 \cdot 115 \\
0.99 \\
0 \cdot 699 \\
0 \cdot 068 \\
0 \cdot 381\end{array}$ \\
\hline
\end{tabular}

* Stratified by age and sex.

† Consumed water noticed to smell or taste unusual on Friday, Saturday, or Sunday.

$¥$ No contact with water noticed to smell or taste unusual on Friday, Saturday, or Sunday but consumed contaminated mains water not noticed to smell or taste unusual on any of the 3 days. Significant at the $0 \cdot 1 \%$ level.

H Significant at the $5 \%$ level. having an unpleasant taste or odour (table 9).

It is of note that in the study group on the Friday, $81 \cdot 1 \%$ consumed contaminated water. On Saturday only $8 \%$ did so and on Sunday $18 \cdot 1 \%$. So by Saturday the message had got through successfully to $92 \%$ of the study group not to drink the water.

\section{Discussion}

The incident this study sought to investigate was a major river pollution. Although the organic contaminants EDD and EMD were present in minute concentrations, they were initially unidentifiable and highly odorous causing much public concern. The incident therefore had the potential for major public health implications.

The investigation showed significant increases in self reporting of 10 symptoms in the study group compared with the control groups. The study group results show a dose-response relationship between exposure to contaminated water and self reported symptoms. When the study group subjects were divided into two groups, however, depending on whether or not they noticed that the water had an unusual taste or odour, no association was found between reporting of symptoms and exposure to contaminated water in subjects who did not notice a taste or odour. Only nausea showed a doseresponse relationship for subjects who did not notice the water to be unusual. Other individual symptoms among those who used contaminated water, but did not notice it to have an unusual taste or odour, did not exhibit a dose-response relationship. In those who noticed the water was unusual, significant doseresponse relationships with individual symptoms were still evident.

Consideration of three important possible sources of bias in this study is needed. Response bias could explain the difference in symptom reporting rates between the study and control groups. For example, 9\% more subjects responded from the study area than the control area. If all these subjects reported symptoms, and say $80 \%$ were exposed to the contaminated water, then adjusting for this, only $6.3 \%$ of people who consumed the water in the study group would have reported symptoms. This is similar to the level of symptom reporting in unaffected areas. There is no evidence to prove or disprove this possible explanation but it seems unlikely. A number of people phoned from the control areas to say they could not see why they needed to fill out the forms as it 
did not affect their area. This logic no doubt affected others who did not bother to phone but who just did not complete the questionnaire. This suggests that the most likely reason for the different response rates is that residents in control group areas did not see the need to reply.

Two different control groups, one in which subjects were at one point advised they were affected, but in reality were not, and an unaffected control area where subjects knew they were unaffected, were used in an attempt to measure recall bias. No difference in symptom reporting between the two control groups was found, suggesting there was not an important degree of recall bias in this study. However, this would only be true if it was certain that those in control group 1 were under the assumption that their water was affected at some point during the incident. How much this view prevailed is unknown.

In addition, there is the possibility of bias due to differential misclassification, that is a tendency for people who felt unwell over the weekend of the incident to attribute it to consumption of water and state they consumed the water when they did not or over estimate the amount they consumed. The possible effects of differential misclassification on the results are unknown, but within the study group, misclassification of symptoms might have depended on the recognition of an unusual taste or odour, which would tend to increase the possibility of spurious associations. It is possible therefore that no significant misclassification affected the results from subjects in the study group not noticing an unusual taste or odour. However, to take account of these possible sources of bias, further evidence of association was sought between the consumption of contaminated water and self reported symptoms by assessing dose-response relationships.

In this study we have assumed that all mains water in the study area was affected equally. It could have been possible that only those who detected an unusual taste or odour were actually exposed to contaminated water whereas households where the unusual taste or odour was not detected did not receive contaminated water. However, this is unlikely. The chemical contaminants polluted the river $120 \mathrm{~km}$ upstream of Worcester, and the contaminants would have been thoroughly mixed in the river. The treatment process at Barbourne works diluted the chemical further. People who received tap water direct from Barbourne works were therefore exposed to the chemicals in equal concentrations. However, only $62 \%$ of subjects in the study group who received the contaminated water noticed it had a peculiar taste or odour despite the fact that analysis of the geographical distribution (by postcode) of subjects who noticed and did not notice the taste or odour found both groups of subjects equally distributed across the city. The reasons for the difference in noticing the taste or odour could be that there were differing concentrations of the chemicals present but is more likely to be due to: (a) the amount of ventilation present (highly volatile substances will be less easily detected in well ventilated areas; (b) how the water was used (a contaminated cold drink is less likely to be noticed than a contaminated hot shower because of the volatile nature of solvents); (c) how close the EDD concentration was to its detection threshold; and (d) people's differing ability to detect odours. The known odour detection threshold of EDD is $0.01 \mu \mathrm{g} /$ $1^{1}$ and the concentration of EDD detected during the incident varied between $0.05 \mu \mathrm{g} / 1$ on Friday 15 April and $0.13 \mu \mathrm{g} / 1$ on Sunday 17 April, so they are very close. Ability to detect an odour varies with age and sex and is affected by other factors such as ill health and smoking. The national geographic smell survey in America showed that for the chemical androstenone, $80 \%$ of $11-19$ year olds could detect an odour whereas only $50 \%$ of those aged 80 or more could do so. ${ }^{2}$ This shows that there is a wide variation within a population in ability to detect an odour and, consequently, it is not surprising that only $62 \%$ noticed the contamination in Worcester.

Those who drank contaminated water but did not notice an unusual taste or odour displayed a rate of symptom reporting similar to neighbouring towns unaffected by the contamination, whereas dose-response relationships were detected among those who noticed the water was unusual. Dose response relationships were observed not just for "odour associated" symptoms such as nausea and headache but also for gastrointestinal symptoms such as stomach pains and diarrhoea. Because of the relatively low response rate in this study it is possible that those who did not notice the water had an unusual taste or odour and yet reported symptoms were under represented. However, there is evidence that individuals who experience symptoms are more likely to respond to questionnaires on the matter than those that are symptom free. ${ }^{3}$ Assuming this holds true in our study, the observed results therefore suggest two possible hypotheses. Firstly, that there exist subpopulations with different levels of susceptibility to EDD and EMD. Secondly, that reporting symptoms may be associated not with contact or drinking the contaminated water but with noticing an unusual taste or odour. The explanation proposed in the latter hypothesis is a well documented phenomenon. ${ }^{4-7}$ It has also been reported in a study of 643 students ${ }^{5}$ that $66 \%$ report illness after smelling one or more of five specific chemicals and a similar study ${ }^{7}$ of 263 people aged 60-90 years reported an illness rate of $57 \%$ after smelling five chemicals. The toxicology data available enables us to explore these hypotheses more fully.

The potential toxicity or otherwise of EDD and EMD needs to be considered in relation to the concentrations involved in this incident. The highest concentrations of EMD and EDD found in the drinking water over the weekend of the incident were $0.13 \mu \mathrm{g} / \mathrm{l}$ for EDD (at 1.30 am Sunday morning) and $0.02 \mu \mathrm{g} / 1$ for EMD (initial reading at 11 am Friday). Concentrations of EMD may have been slightly higher earlier on Friday but at their source in Wem the chemicals were only 25 and 70 times 
more concentrated $(1.44 \mu \mathrm{g} / 1$ for $\mathrm{EMD}$ and $3 \cdot 13 \mu \mathrm{g} / 1$ for EDD). Whether chemicals at these concentrations are harmful depends on their degree of toxicity. EMD and EDD are solvents whose toxicity is poorly known; their parent compounds are dioxolane and dioxane respectively. Being solvents these give off an odour which could cause nausea, headache, and possibly dizziness. The UK recommended safe level of exposure to dioxane vapour for 8 hours is $90 \mathrm{mg} / \mathrm{m}^{3}{ }^{8}$ Acute exposure to dioxane vapours at $700-1000 \mathrm{mg} / \mathrm{m}^{3}$ (for a few minutes) leads to irritation to the nose and eyes. ${ }^{9}$ Safe limits are not set for concentrations in water but at concentrations of several grams per kg bodyweight it is likely to cause irritation of mucosal surfaces including gastrointestinal irritation, so symptoms might include diarrhoea, vomiting, and stomach pains. The recommended limit of dioxane intake is equivalent to the ingestion of $1800 \mathrm{mg}$ in a day. Of those who reported symptoms in the study group the average total consumption of contaminated water over the three days was 1 litre. The peak concentration of EDD measured in drinking water over the three days was $0.13 \mu \mathrm{g}$ / 1 and therefore it is reasonable to assume that the total ingestion of EDD by an individual is likely to have been no more than about $0 \cdot 13 \mu \mathrm{g}$. This is 10 million times smaller than the UK recommended level of dioxane, EDD's parent compound.

There is little information on dioxolane the parent compound of EMD but in a Russian study, ${ }^{10}$ workers were occupationally exposed for between 10 and 20 years to vapour levels of between 20 and $100 \mathrm{mg} / \mathrm{m}^{3}$ (equivalent to ingesting 400-2000 mg per day). No adverse effect on morbidity or mortality was observed. The estimated total ingestion of EMD by an individual in the Worcester study was $0.02 \mu \mathrm{g}$ - that is, 100 million times less than the daily exposure in the Russian study. Although safety levels cannot be translated directly, there is no chemical reason why EDD and EMD should be any more toxic than their parent compounds.

The toxicity data therefore support the second hypothesis, that symptoms were associated with noticing the unusual taste or odour of the water, since all previous measured toxic levels of parent compounds of EDD and EMD have been several million times larger than those observed in this incident. The fact that by Saturday only $8 \%$ of the sampled population consumed the contaminated water suggests a high level of awareness of the water problem was reached in the population in a relatively short time. This level of awareness was very commendable in terms of a public communication exercise but it would not be surprising if the anxiety associated with the media message caused gastrointestinal upsets and other symptoms in people who realised they had consumed contaminated water. As the potential toxicity of the contamination was unknown at the beginning of the incident, some anxietyinduced minor illness resulting from warnings of contaminated tap water can be justified. However, it should not be ignored when assessing the impact on the public of such an incident.

We are grateful to Dr Mary O'Mahoney and Dr Ian Blair for help in questionnaire and study design, to Dr Tony Hughes, Senior Lecturer in Medical Statistics, Department of Epidemiology, University of Bristol, and Jane Bruce, Statistician, Communicable Disease Surveillance Centre, London, for epidemiological and statistical advice. Also to Dr Alan Jones, Consultant Clinical Toxicologist, National Poisons Information Service, Birmingham for advice on the toxicology.

1 Preti G, Gittelman TS, Staudte PB, Lultweiler P. Letting the nose lead the way - malodorous components in drinking water. Anal Chem 1993;65:699A-702A

2 Wysocki CJ. Gilbert AN. National geographic smell survey. Effects of age are heterogenous. Ann NYAcad Sci 1989; 561:12-28.

3 Tennant A, Badley GM. A confidence interval approach to investigating non-response bias and monitoring response to postal questionnaires. 7 Epidemiol Community Health 1991;45:81-5.

4 Bell IR, Schwartz GE, Amend D, Peterson JM, Stini WA. Sensitization to early life stress and response to chemical odors in older adults. Biol Psychiatry 1994;35(11):857-63.

5 Bell IR, Schwartz GE, Peterson JM. Amend D. Self-reported illness from chemical odors in young adults without clinical syndromes or occupational exposures. Arch Environ Health $1993 ; 48(1): 6-13$

6 Shusterman D. Critical review: the health significance of environmental odor pollution. Arch Environ Health 1992; 47(1):76-87.

7 Bell IR, Schwartz GE, Peterson JM, Amend D, Stini WA. Possible time-dependent sensitization to xenobiotics: selfreported illness from chemical odors, foods, and opiate drugs in an older adult population. Arch Envinn Health 1993;48(5):315-27.

8 National Institute for Occupational Safety and Health. Criteria for Recommended Standard. Occupational exposure to dioxane. NIOSH, 1977: Document no 77-226.

9 Silverman L. Respiratory air flow characteristics and their relation to certain lung conditions occurring in industry. foumal of Industrial Hygiene and Toxicology 1946;28:18396

10 Lomonova GV, Vinogradova VK. Materials for the hygenic normalisation of formal-glycol in the air of production area. The Institute for Labour Hygiene and Occupational Health, 22 April 1974 (USSR) 